OPEN ACCESS

Edited by:

Robert Kourist

Graz University of Technology, Austria

Reviewed by:

Valerio Ferrario,

University of Stuttgart, Germany

Karl Hult,

Royal Institute of Technology, Sweden

*Correspondence:

Alessandro Pellis

alessandro.pellis@boku.ac.at

${ }^{\dagger}$ Present Address:

Sabine Zitzenbacher,

Richard Bittner AG, Feldkirchen,

Austria;

Enrique Herrero Acero,

Glanzstoff Industries $\mathrm{GmbH}$,

St. Poelten, Austria

Specialty section:

This article was submitted to Microbiotechnology, Ecotoxicology

and Bioremediation,

a section of the journal

Frontiers in Microbiology

Received: 28 March 2017 Accepted: 09 May 2017

Published: 24 May 2017

Citation

Gamerith C, Vastano M, Ghorbanpour SM, Zitzenbacher S, Ribitsch D, Zumstein MT, Sander M,

Herrero Acero E, Pellis A and

Guebitz GM (2017) Enzymatic

Degradation of Aromatic and Aliphatic

Polyesters by P. pastoris Expressed

Cutinase 1 from Thermobifida cellulosilytica. Front. Microbiol. 8:938.

doi: 10.3389/fmicb.2017.00938

\section{Enzymatic Degradation of Aromatic and Aliphatic Polyesters by $P$. pastoris Expressed Cutinase 1 from Thermobifida cellulosilytica}

\author{
Caroline Gamerith ${ }^{1}$, Marco Vastano ${ }^{2,3}$, Sahar M. Ghorbanpour ${ }^{2}$, Sabine Zitzenbacher ${ }^{1+}$, \\ Doris Ribitsch ${ }^{1,2}$, Michael T. Zumstein ${ }^{4}$, Michael Sander ${ }^{4}$, Enrique Herrero Acero ${ }^{1 \dagger}$, \\ Alessandro Pellis ${ }^{2 *}$ and Georg M. Guebitz ${ }^{1,2}$ \\ ${ }^{1}$ Austrian Centre of Industrial Biotechnology, Tulln, Austria, ${ }^{2}$ Institute of Environmental Biotechnology, University of Natural \\ Resources and Life Sciences Vienna, Tulln, Austria, ${ }^{3}$ Dipartimento di Scienze Chimiche, Universita degli Studi di Napoli \\ Federico II, Naples, Italy, ${ }^{4}$ Institute of Biogeochemistry and Pollutant Dynamics, ETH Zurich, Zurich, Switzerland
}

To study hydrolysis of aromatic and aliphatic polyesters cutinase 1 from Thermobifida cellulosilytica (Thc_Cut1) was expressed in P. pastoris. No significant differences between the expression of native Thc_Cut1 and of two glycosylation site knock out mutants (Thc_Cut1_koAsn and Thc_Cut1_koST) concerning the total extracellular protein concentration and volumetric activity were observed. Hydrolysis of poly(ethylene terephthalate) (PET) was shown for all three enzymes based on quantification of released products by HPLC and similar concentrations of released terephthalic acid (TPA) and mono(2-hydroxyethyl) terephthalate (MHET) were detected for all enzymes. Both tested aliphatic polyesters poly(butylene succinate) (PBS) and poly(3-hydroxybutyrate-co-3hydroxyvalerate) (PHBV) were hydrolyzed by Thc_Cut1 and Thc_Cut1_koST, although PBS was hydrolyzed to significantly higher extent than PHBV. These findings were also confirmed via quartz crystal microbalance (QCM) analysis; for PHBV only a small mass change was observed while the mass of PBS thin films decreased by 93\% upon enzymatic hydrolysis with Thc_Cut1. Although both enzymes led to similar concentrations of released products upon hydrolysis of PET and PHBV, Thc_Cut1_koST was found to be significantly more active on PBS than the native Thc_Cut1. Hydrolysis of PBS films by Thc_Cut1 and Thc_Cut1_koST was followed by weight loss and scanning electron microscopy (SEM). Within $96 \mathrm{~h}$ of hydrolysis up to 92 and $41 \%$ of weight loss were detected with Thc_Cut1_koST and Thc_Cut1, respectively. Furthermore, SEM characterization of PBS films clearly showed that enzyme tretment resulted in morphological changes of the film surface.

Keywords: cutinase, Thermobifida cellulosilytica, Pichia pastoris, poly(3-hydroxybutyrate-co-3-hydroxyvalerate), poly(butylene succinate), poly(ethylene terephthalate), enzymatic hydrolysis, aliphatic polyesters 


\section{INTRODUCTION}

Plastic materials are ubiquitous in our daily life and although the annual European production is in a steady state since a decade, the global production is constantly increasing ${ }^{1}$. Most conventional plastics such as polyethylene, polypropylene, polystyrene, poly(vinyl chloride), and poly(ethylene terephthalate) (PET) are fully petrol-based and not biodegradable. The release of those plastic materials into the environment and their subsequent accumulation poses environmental risks and negatively impacts ecosystems, including the extreme consequences of plastic patch formation in rivers and oceans (Eriksen et al., 2014; Lechner et al., 2014). Considerable effort has been directed toward implementing bio-based plastics as environmentally-friendly alternatives to the traditionally petrol-derived materials. In particular, the substitution of polyesters such as PET and polybutyrate adipate terephthalate (PBAT) seems to be imminent since several market-leading companies are focusing their investigations on production of monomers derived from renewable biomass. Recent innovations also allow the biotechnological production of bio-based monomers from renewable carbon, enabling the replacement of petrochemical building blocks (Pellis et al., 2016c,d). These bio-based building blocks can be either produced by microbial conversions of various feedstocks or with combined biotechnological-chemical pathways that lead to various monomers such as 1,4-butanediol and adipic acid (used for the production of PBAT) (Harmsen et al., 2014). Fermentation of sugars or various other feedstocks, including lignocellulose (Pinazo et al., 2015), can also be used to obtain succinic and lactic acid for the production of poly(butylene succinate) (PBS) and poly(lactic acid) respectively. Poly(hydroxyalkanoates) (PHAs) on the other hand are directly produced by natural or engineered microorganisms. Mulch films are the most common and highly consumed plastic products in agriculture and their widespread use has led to an increase in environmental wastes. Therefore, commercially available mulch films are usually made of biodegradable plastics, with PBS as the main component (Koitabashi et al., 2012). In recent years there has been conservable interest in the substitution of PET with plantderived poly(ethylene furanoate) (PEF) (Pellis et al., 2016b). The monomers for PEF (2,5-furandicarboxylic acid and ethylene glycol) can be $100 \%$ produced from renewable feedstocks (Pellis et al., 2016d).

The potential of enzymes for degradation of polymer building blocks has been studied by several groups. Various enzymes belonging to the cutinase family were reported to hydrolyze PET, the most used polyester (Yoon et al., 2002; Vertommen et al., 2005; Herzog et al., 2006; Heumann et al., 2006; Donelli et al., 2009; Herrero Acero et al., 2011; Ribitsch et al., 2011, 2012; Kanelli et al., 2015). Moreover, reports on the biocatalyzed hydrolysis of poly(lactic acid) (Pellis et al., 2015, in press; Ortner et al., 2017), poly(butylene succinate) (Hu et al., 2016) and poly(ethylene furanoate) (Pellis et al., 2016b) using similar biocatalysts were also described and

${ }^{1}$ Plastics Europe Plastics-the Facts 2015, 2015 (Accessed May 17, 2016). certify the importance of such processes in the optics of a sustainable development (Clark et al., 2016; Pellis et al., 2016c). Despite the high industrial potential reported for cutinases from Thermobifida spp., these enzymes have usually been obtained by intracellular recombinant expression in E. coli (Herrero Acero et al., 2011; Su et al., 2013; Roth et al., 2014; Then et al., 2016), an approach that hampers the scale-up of the production process. Lately the methylotrophic yeast $P$. pastoris gained increasing interest as expression system for recombinant proteins for basic research as well as for industrial applications as shown by the number of filed patents (Bollok et al., 2009). In addition to the ability of $P$. pastoris to perform post-translational modifications one of the main advantages is that the recombinant proteins can often be secreted at high concentrations while maintaining their correct folding and activity (Cregg et al., 1993; Cereghino and Cregg, 2000; Ahmad et al., 2014; Hu et al., 2016). Furthermore, this host usually allows a simple production scale-up by changing from shaking flaks expressions to (fedbatch) fermenters (Schilling et al., 2002; Johnson et al., 2003; Zhao et al., 2008). Several commercial proteins are produced in P. pastoris, including recombinant Tritirachium album Proteinase K (Thermo Scientific, Waltham, MA, USA), Trypsin (Roche Applied Science, Germany), and nitrate reductase (The Nitrate Elimination Co., Lake Linden, MI, USA; Ahmad et al., 2014). In the past, successful expressions of cutinases from Fusarium solani (Kwon et al., 2009; Hu et al., 2016), Alternaria brassicicola (Koschorreck et al., 2010), Glomerella cingulata (Seman et al., 2014), and Trichoderma harzianum (Rubio et al., 2008) in P. pastoris have been reported. In this study, cutinase 1 from Thermobifida cellulosilytica (Thc_Cut1) as well as two glycosylation knock out mutants (Thc_Cut1_ko) were cloned and overexpressed in P. pastoris and screened for their ability to hydrolyze the aromatic polyester (PET) and the aliphatic polyesters [Poly(3-hydroxybutyrate-co3-hydroxyvalerate) (PHBV) and PBS].

\section{MATERIALS AND METHODS}

\section{Chemicals and Reagents}

Restriction enzymes, antarctic phosphatase, T4 DNA ligase as well as Endo $\mathrm{H}_{\mathrm{f}}$ were obtained from New England Biolabs (USA). Synthetic genes of $P$. pastoris codon optimized Thc_Cut1 and glycosylation site knock out mutants (Thc_Cut1_ko_Asn and Thc_Cut1_ko_ST) cloned into pMK-T were ordered from GeneArt (Germany). Pro-Q ${ }^{\circledR}$ Emerald 300 Glycoprotein Gel and Blot Stain Kit (P21857), CandyCane glycoprotein molecular weight standard (C21852) as well as P. pastoris KM71H strain and expression vector pPICZ $\alpha \mathrm{B}$ were acquired from ThermoFisher Scientific (USA). E. coli XL-10 cells were purchased from Agilent (USA). PureYield ${ }^{\mathrm{TM}}$ Plasmid Midiprep System, SV Gel and PCR Clean-Up System Kits and Mini-PROTEAN ${ }^{\circledR}$ TGX (StainFree $^{\mathrm{TM}}$ ) Precast Gels were obtained from Promega (Germany) or BioRad (USA), respectively. Peptone, Yeast extract and DifCo yeast nitrogen base were purchased from Becton Dickinson (USA) and Zeocin ${ }^{\mathrm{TM}}$ was obtained from Eubio (Austria). All other chemicals were of the highest available purity and ordered 
from Sigma-Aldrich. PET powder obtained from still water bottle from Cristaline ${ }^{\circledR}$ was kindly provided by Carbios (St-Beauzire, France) and was previously characterized (Gamerith et al., in press). PHBV was purchased from Metabolix while PBS was purchased from Sigma-Aldrich. The PBS material used for quartz crystal microbalance (QCM) experiments was obtained from BASF and the physicochemical properties of this polyester were previously reported (Zumstein et al., 2016).

\section{Designing of thc_Cut1 Glycosylation Site Knock out Mutants}

Using NetNGlyc 1.0 server (Technical University of Denmark) five possible $\mathrm{N}$-glycosylation sites were predicted in the native Thc_Cut1 sequence (GenBank accession no. ADV92526.1). Asparagine (Asn) at amino acid position 10 is directly followed by a proline which makes glycosylation unlikely due to conformational constraints. Also for Asn at position 233 the glycosylation potential was lower compared to the other potential glycosylation sites according to the prediction. Therefore, the three glycosylation sites at Asn 29, Asn 49, and Asn 161 were knocked out by changing the nucleotide sequence accordingly, resulting in two triple knockout mutants (for details see Table 1). Synthetic genes of the designed glycosylation site knock out mutants (Thc_Cut1_ko) cloned into pMK-T were ordered from GeneArt.

\section{General Recombinant DNA Techniques}

All general recombinant DNA techniques described in this work were performed following previously reported standard protocols (Sambrook et al., 1989). Digestion of cloning vector $(\mathrm{pMK}-\mathrm{T})$ and expression vector $(\mathrm{pPICZ} \alpha \mathrm{B})$ were performed with NotI Hf and XhoI, dephosphorylation was performed by antarctic phosphatase and T4 DNA ligase was used for ligation according to manufacturer's protocols (New England Biolabs). Plasmids and DNA fragments were purified by PureYield ${ }^{\mathrm{TM}}$ Plasmid Midiprep System Kit or Wizard $^{\circledR}$ SV Gel and PCR Clean-Up System Kit. After transformation of E. coli XL-10 cells and plasmid purification pPICZ $\alpha$ B_Thc_Cut1 and pPICZ $\alpha$ B_Thc_Cut1_ko constructs were sequenced by LGC Genomics in order to confirm the DNA sequence.

TABLE 1 | Detailed design of Thc_Cut1 glycosylation site triple knock out mutants (Thc_Cut1_ko).

\begin{tabular}{llllllll}
\hline Name & \multicolumn{3}{c}{ AA mutations } & & & \multicolumn{2}{c}{ Nucleotide mutations } \\
\cline { 2 - 3 } & Position & From & To & & From & To \\
\hline Thc_Cut1_kO_Asn & 29 & Asn & Asp & AAC & GAC \\
& 49 & Asn & Asp & AAC & GAC \\
& 161 & Asn & Asp & AAC & GAC \\
\hline Thc_Cut1_kO_ST & 31 & Ser & Ala & TCT & GCA \\
& 51 & Thr & Ala & ACT & GCA \\
& 163 & Ser & Ala & TCC & GCA
\end{tabular}

\section{Transformation into $P$. pastoris $\mathrm{KM} 71 \mathrm{H}$ and Screening of Transformants}

Eighty Milliliter $80 \mu \mathrm{L}$ of electrocompetent $P$. pastoris $\mathrm{KM} 71 \mathrm{H}$ cells were transformed with SacI-Hf linearized pPICZ $\alpha$ B_Thc_Cut1 or pPICZ $\alpha$ B_Thc_Cut1_ko by electroporation (MikroPulser ${ }^{\mathrm{TM}}$, Bio-Rad) according to the manual instructions. Transformed cells were spread on yeast extract peptone dextrose sorbitol medium agar plates [YPDS, $1 \%(w / v)$ yeast extract, $2 \%(w / v)$ peptone, $2 \%(w / v)$ glucose, 1 M sorbitol, $2 \%(w / v)$ agar] containing $0.1 \mathrm{mg} / \mathrm{mL} \mathrm{Zeocin}{ }^{\mathrm{TM}}$ and incubated at $28^{\circ} \mathrm{C}$ for $3-5$ days. Transformants were cultivated in YPD medium in 96-deep-well-plates and screened for multicopy integrants on YPD agar plates $[1 \%(w / v)$ yeast extract, $2 \%$ $(w / v)$ peptone, $2 \%(w / v)$ glucose, $2 \%(w / v)$ agar] containing $0.1-2$ $\mathrm{mg} / \mathrm{mL}$ Zeocin $^{\mathrm{TM}}$. Stock cultures of selected clones were stored at $-80^{\circ} \mathrm{C}$.

\section{P. pastoris Shaking Flask Fermentation}

For enzyme production, $1 \mathrm{~L}$ baffled shaking flasks containing $250 \mathrm{~mL}$ of buffered glycerol complex medium [BMGY; 1\% $(w / v)$ yeast extract, $2 \%(w / v)$ peptone, $1 \%(\mathrm{v} / v)$ glycerol, $3.4 \%$ $(w / v)$ yeast nitrogen base, $4 \times 10^{-5} \%$ biotin, $100 \mathrm{mM}$ potassium phosphate buffer $\mathrm{pH}$ 6.0] were inoculated with $P$. pastoris $\mathrm{KM} 71 \mathrm{H}$ transformants and incubated at $28^{\circ} \mathrm{C}$ and $150 \mathrm{rpm}$ for approximately $16-18 \mathrm{~h}$. Cells were harvested by centrifugation $\left(3,000 \times \mathrm{g}, 8 \mathrm{~min}, 22^{\circ} \mathrm{C}\right)$ and the cell pellet was re-suspended in one-tenth of the original volume $(75 \mathrm{~mL}$ culture volume in $300 \mathrm{~mL}$ shaking flasks). Enzyme expression was induced by the addition of methanol to a final concentration of $1 \%(v / v)$. Methanol was added twice daily to a final concentration of $1 \%$ $(v / v)$ to sustain the induction. During fermentation, samples were collected by centrifugation $\left(14,000 \mathrm{rpm}, 5 \mathrm{~min}, 22^{\circ} \mathrm{C}\right)$ and supernatants were stored at $-20^{\circ} \mathrm{C}$ until further use. After up to $120 \mathrm{~h}$ of enzyme expression, cells were harvested by centrifugation $\left(4,500 \mathrm{rpm}, 4^{\circ} \mathrm{C}, 20 \mathrm{~min}\right)$ and the supernatant was stored at $-20^{\circ} \mathrm{C}$ until protein purification.

\section{Immobilized Metal Ion Affinity Chromatography for Enzyme Purification}

The enzyme purification from the fermentation supernatants was performed via affinity chromatography (ÄKTA purifier, GE Healthcare) using HisTrap ${ }^{\mathrm{TM}}$ excel $5 \mathrm{~mL}$ columns (GE Healthcare). After sample loading (flow rate $2 \mathrm{~mL} / \mathrm{min}$ ) the column was washed with 7 column volumes $(\mathrm{CV})$ of equilibration buffer (20 mM NaH${ }_{2} \mathrm{PO}_{4}, 500 \mathrm{mM} \mathrm{NaCl}, \mathrm{pH}$ 7.4) followed by $3 \mathrm{CV}$ of $1 \%$ elution buffer $\left(20 \mathrm{mM} \mathrm{NaH} \mathrm{PO}_{4}, 500 \mathrm{mM} \mathrm{NaCl}\right.$, $500 \mathrm{mM}$ imidazole, $\mathrm{pH}$ 7.4). The enzyme was eluted with $45 \%$ elution buffer for $6 \mathrm{CV}$. Finally the column was washed with $100 \%$ elution buffer for $3 \mathrm{CV}$ and stored in a $20 \%$ ethanol solution. Proteins were detected at $280 \mathrm{~nm}$. SDS-PAGE analysis of purification fractions was performed in order to confirm the presence of Thc_Cut1 or Thc_Cut1_ko in the pooled fractions. PD-10 columns (Sephadex ${ }^{\mathrm{TM}}$ G-25 Medium, GE Healthcare) were used to exchange the buffer to $100 \mathrm{mM} \mathrm{KH} \mathrm{KO}_{4} / \mathrm{K}_{2} \mathrm{HPO}_{4}$ $\mathrm{pH} 7.0$ before storage of purified proteins at $-20^{\circ} \mathrm{C}$ until further usage. 


\section{Expression Analysis and Enzyme Characterization SDS-PAGE and Glycostain Analysis}

SDS-PAGE of fermentation supernatant samples withdrawn at different time points was performed according to standard conditions (Laemmli, 1970). After staining with Coomassie Brilliant Blue R-250, SDS PAGE gels were imaged using a ChemiDoc (Chemidoc ${ }^{\mathrm{TM}}$ MP Imaging System, Bio-Rad). Stain free SDS-PAGE gels were directly visualized using a ChemiDoc (Chemidoc ${ }^{\text {TM }}$ MP Imaging System, Bio-Rad) without further treatment. Deglycosylation of Thc_Cut1 and Thc_Cut1_ko mutants was performed using Endo $\mathrm{H}_{\mathrm{f}}$ according to manufacturer's instructions (New England Biolabs). Glycostain gels were prepared according to Pro-Q ${ }^{\circledR}$ Emerald 300 Glycoprotein Gel and Blot Stain Kit manual and detected by G-Box or hand-held UV lamp at $300 \mathrm{~nm}$.

\section{Protein Analysis}

Total protein concentrations in the fermentation supernatants (from different time points) as well as protein concentrations of purified enzymes were determined using the Bradford assay (BioRad) according to manual instructions and using bovine serum albumin (BSA) as standard.

\section{Esterase Activity Assay}

Esterase activity of fermentation supernatants (from different time points) and of purified enzymes was measured using $p$ nitrophenyl butyrate ( $\mathrm{pNPB}$ ) as soluble substrate according to Gamerith et al. using the experimentally determined extinction coefficient $\left(\varepsilon=9.7 \mathrm{~mL} \mu \mathrm{mol}^{-1} \mathrm{~cm}^{-1}\right)$ (Gamerith et al., in press).

\section{Enzymatic Hydrolysis of Polyester Substrates}

For hydrolysis reactions, $50 \mathrm{mg}$ of PET powder or $5 \mathrm{mg}$ of aliphatic polyester powders (PHBV, PBS) were weighed and incubated with $5 \mu \mathrm{M}$ of enzyme (Thc_Cut1 or Thc_Cut1_koST) diluted in a final volume of $1 \mathrm{~mL}$ in $\mathrm{KH}_{2} \mathrm{PO}_{4} / \mathrm{K}_{2} \mathrm{HPO}_{4}(1$ $\mathrm{M}, \mathrm{pH}$ 8.0). In case of PBS films, pieces of $0.5 \times 1.0 \mathrm{~cm}$ were cut and washed in three serial steps $(5 \mathrm{~g} / \mathrm{L}$ Triton $\mathrm{X}$ $100,100 \mathrm{mM} \mathrm{Na}_{2} \mathrm{CO}_{3}$, and $\mathrm{ddH}_{2} \mathrm{O}$; each for $30 \mathrm{~min}$ at $50^{\circ} \mathrm{C}$ and $100 \mathrm{rpm}$ ) prior to hydrolysis reactions in order to remove possible surface contaminations (Pellis et al., 2015, in press; Gamerith et al., 2016). Incubations were performed in $2 \mathrm{~mL}$ tubes at $100 \mathrm{rpm}$ and $65^{\circ} \mathrm{C}$ for different time frames. The released acids, alcohols and oligomers, namely: terephthalic acid (TPA) and mono(2-hydroxyethyl) terephthalate (MHET) for PET; succinic acid (SA) and 1,4-butanediol (BDO) for PBS and 3-hydroxybutyric acid (3-HBA) for PHBV were analyzed by HPLC using either a diode array detector (DAD) or a refractive index detector (RI). As a blank, polyester substrates were incubated in $\mathrm{KH}_{2} \mathrm{PO}_{4} / \mathrm{K}_{2} \mathrm{HPO}_{4}(1 \mathrm{M}, \mathrm{pH}$ 8.0) without enzyme. Enzyme blanks were also performed by incubating $5 \mu \mathrm{M}$ solutions of enzymes in $\mathrm{KH}_{2} \mathrm{PO}_{4} / \mathrm{K}_{2} \mathrm{HPO}_{4}(1 \mathrm{M}, \mathrm{pH}$ 8.0) without polyester substrate. All hydrolysis experiments were performed in triplicates.

\section{Analysis of Soluble Monomers and Oligomers Released by High Performance Liquid Chromatography (HPLC-DAD or HPLC-RI)} HPLC-DAD Detection of TPA and MHET

HPLC analysis of released products upon enzymatic hydrolysis of PET was performed as recently described by Gamerith et al. (in press). Briefly, after enzyme treatment of polyester powders the enzyme was precipitated with ice-cold methanol. After acidification to $\mathrm{pH} 3.5$, samples were centrifuged (Hettich MIKRO $200 \mathrm{R}$, Tuttlingen, Germany) at $14,000 \mathrm{rpm}$ at $0^{\circ} \mathrm{C}$ for $15 \mathrm{~min}$, filtered $(0.45 \mu \mathrm{m}$ nylon) and transferred to HPLC vials. For HPLC (Agilent Technologies, 1260 Infinity) analysis, a reversed phase column C18 (YMC 30, $250 \times 4.6 \mathrm{~mm} \mathrm{ID,} \mathrm{S-5}$ $\mu \mathrm{m})$ was used. Analysis was carried out with constant $10 \% 0.01$ $\mathrm{N}$ formic acid and starting with $85 \%$ water and 5\% methanol, gradual ( $1 \mathrm{~min}$ ) to $10 \%$ methanol, gradual (to $8 \mathrm{~min}$ ) to $50 \%$ methanol and gradual (to $10 \mathrm{~min}$ ) to $90 \%$ methanol, back to starting position with a $7 \mathrm{~min}$ post run. The flow rate was set to $0.85 \mathrm{~mL} \mathrm{~min}{ }^{-1}$ and the column was maintained at a temperature of $40^{\circ} \mathrm{C}$. The injection volume was set to $10 \mu \mathrm{L}$. Detection of the analytes was performed with a photodiode array detector (Agilent Technologies, 1290 Infinity II) at a wavelength of $241 \mathrm{~nm}$. Standards of TPA and bis(hydroxyethyl)terephthalate (BHET) were prepared in $\mathrm{KH}_{2} \mathrm{PO}_{4} / \mathrm{K}_{2} \mathrm{HPO}_{4}(1 \mathrm{M}, \mathrm{pH}$ 8.0) in a range of $0.005-0.5 \mathrm{mM}$ and treated the same way as samples.

\section{HPLC-RI Detection of SA, BDO, and 3-HBA}

HPLC-RI detection of released products from PHBV and PBS was performed as previously reported by Pellis et al. (2015). Briefly, hydrolysis samples were precipitated following the Carrez method and filtered through $0.45 \mu \mathrm{m}$ Nylon filters (GVS, Indianapolis, USA). The analytes were separated by HPLC using refractive index detection (1100 series, Agilent Technologies, Palo Alto, CA) equipped with an ICSep-ION-300 column (Transgenomic Organic, San Jose, CA) of $300 \mathrm{~mm}$ by $7.8 \mathrm{~mm}$ and $7 \mu \mathrm{m}$ particle diameter. Column temperature was maintained at $45^{\circ} \mathrm{C}$. Samples $(40 \mu \mathrm{L})$ were injected and separated by isocratic elution for $40 \mathrm{~min}$ at $0.325 \mathrm{~mL} \mathrm{~min}^{-1}$ in $0.005 \mathrm{M} \mathrm{H}_{2} \mathrm{SO}_{4}$ as the mobile phase. Standards of SA, BDO and 3-HBA were prepared in $\mathrm{KH}_{2} \mathrm{PO}_{4} / \mathrm{K}_{2} \mathrm{HPO}_{4}(1 \mathrm{M}, \mathrm{pH} 8.0)$ in a range of $0.5-100 \mathrm{mM}$ and treated the same way as samples.

\section{Enzymatic Hydrolysis Measurements using a Quartz Crystal Microbalance (QCM)}

The hydrolysis of spin-coated PHBV and PBS thin films by Thc_Cut1 was measured by QCM as previously reported (Zumstein et al., 2016). In brief, we spin coated thin films from chloroform solutions containing the respective polyester (concentration: $0.5 \% \mathrm{w} / \mathrm{w}$ ) onto the surfaces of gold-coated QCM sensors. After air-drying the sensors, they were incubated in a buffered solution [ $3 \mathrm{mM}$ tris(hydroxymethyl)-aminomethane, $10 \mathrm{mM}$ potassium chloride, $\mathrm{pH}$ 7.0] for $14 \mathrm{~h}$. The sensors were subsequently mounted into the flow cells of a QCM instrument (model E4, Q-sense) and rinsed with buffered solution of the same composition at a volumetric flow rate of $20 \mu \mathrm{L} / \mathrm{min}$ 
and a temperature of $40^{\circ} \mathrm{C}$. Upon attaining stable resonance frequencies of the fundamental tone and several oscillation overtones, we switched to delivering solutions that contained Thc_Cut1 $(2.07 \mu \mathrm{g} / \mathrm{mL})$ but otherwise were identical in $\mathrm{pH}$ and ionic composition to the solutions used for equilibration. We subsequently monitored changes in the resonance frequencies over the course of the hydrolysis experiment and related these frequency changes to adlayer mass changes using the Sauerbrey equation. We used the fifth overtone of the oscillation for calculations and data plotting. To measure the fraction of coated polyester dry mass that was removed over the course of the hydrolysis experiment, we measured the resonance frequency of each sensor in air after the experiment as well as before and after the initial polyester spin coating step. We note that Thc_Cut1 used in QCM experiments was expressed in E. coli.

\section{Scanning Electron Microscopy (SEM)}

PBS films morphology was qualitatively assessed through scanning electron microscopy (SEM). Control PBS (without any enzymatic treatment) and enzymatically hydrolyzed films (after 24, 48, 72, and $96 \mathrm{~h}$ ) were surface characterized. All SEM images were acquired collecting secondary electrons on a Hitachi 3030TM (Metrohm INULA GmbH, Austria) working at EDX acceleration voltage.

\section{RESULTS AND DISCUSSION}

\section{Glycosylation Site Knock out Mutant design, Vector Construction, and Transformation in $P$. pastoris}

In its natural hosts or when heterologously expressed in E. coli (Herrero Acero et al., 2011; Su et al., 2013; Roth et al., 2014; Then et al., 2016) Thermobifida spp. cutinases are not glycosylated. In contrast, expression in $P$. pastoris may lead to glycosylation which can have positive effects such as increased stability, as previously shown for a Thermobifida xylanase (Zhao et al., 2015), human aquaporin 10 (Öberg et al., 2011) and Rhizopus chinensis lipase (Yang et al., 2015). Shirke et al. also recently reported that glycosylation stabilizes a $P$. pastoris-expressed cutinase from Thiellavia terrestris by inhibiting its thermal aggregation (Shirke et al., 2017). On the other hand, glycosylation may also have negative effects, as shown for example for a lipase from Rhizomucor miehei which had decreased activity upon N-glycosylation (Liu et al., 2014). Therefore, it was important to investigate the influence of glycosylation on the activity and stability of Thc_Cutl when expressed in $P$. pastoris. Hence, two glycosylation site triple knock out mutants were designed (Figure 1). The recombinant pPICZ $\alpha$ B_Thc_Cut1 and pPICZ $\alpha$ B_Thc_Cut1_ko plasmids contained the codon optimized gene of wild type or mutated Thc_Cut1, the methanol inducible alcoholoxidase 1 promoter (AOX1), the $S$. cerevisiae $\alpha$-factor secretion signal, a C-terminal $6 \mathrm{x}$ His-Tag and a transcription termination signal. The tightly regulated AOX1 promoter holds advantages for overexpression of proteins since cells are not stressed by the accumulation of recombinant protein during growth phase. Even the production of proteins that are toxic to $P$. pastoris is possible by uncoupling the growth from the production phase (Ahmad et al., 2014). The most commonly employed method of generating multi-copy expression strains in $P$. pastoris is based on direct screening of transformants on agar plates containing increasing concentrations of antibiotics (e.g., $0.1-2 \mathrm{mg} / \mathrm{mL}$ of Zeocin ${ }^{\mathrm{TM}}$ ) (Ahmad et al., 2014). After successful transformation by electroporation the selection of Thc_Cut1 and Thc_Cut1_ko transformants yielded clones that might contain multi-copy integrations as shown by growth on $2 \mathrm{mg} / \mathrm{mL}$ Zeocin ${ }^{\mathrm{TM}}$. A direct correlation between copy number and expression level has been shown especially for intracellular expression (Vassileva et al., 2001; Marx et al., 2009), but this direct correlation is not necessarily valid for secreted proteins (Marx et al., 2009).

\section{Analysis of Cutinase Expression in Shaking-Flasks}

After successful transformation and screening on high Zeocin ${ }^{\mathrm{TM}}$ YPD agar plates the best growing $P$. pastoris $\mathrm{KM} 71 \mathrm{H}$ transformants of each enzyme were chosen for enzyme production in shaking flasks. Enzyme expression was induced by the addition of methanol and during fermentation several
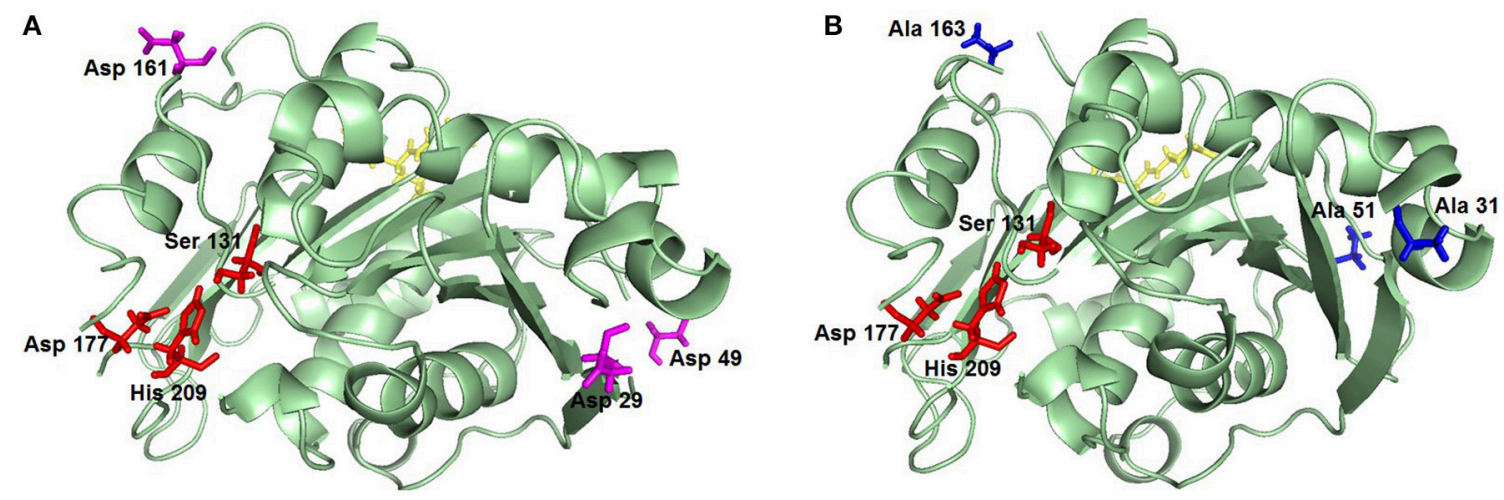

FIGURE 1 | Representation of Thc_Cut1 glycosylation site knockout mutants. (A) Thc_Cut1_koAsn, (B) Thc_Cut1_koST; mutated AA are in pink (A) and blue (B), active site residues are in red, ALE linker sequence for $6 \times$ His-Tag is shown in yellow. 
supernatant samples were collected by centrifugation. Analysis of these supernatant samples drawn at different time points during shaking flask fermentations by SDS-PAGE clearly showed that methanol induction successfully stimulated the expression of cutinases (Figure 2).

Although hyperglycosylation of heterologous proteins is more common in S. cerevisiae (Grinna and Tschopp, 1989), expression in $P$. pastoris can also lead to hyperglycosylation mainly attributed to N-mannosylation (Bretthauer and Castellino, 1999; Várnai et al., 2014). Glycosylation may affect the migration of the proteins on SDS-PAGE or, in case of heterogeneous glycosylation, may result in smears (Bretthauer and Castellino, 1999; Várnai et al., 2014). It was previously reported that heterologous expression of cutinase CUTAB1 from Alternaria brassiciola in $P$. pastoris led to a single band on SDS-PAGE when applied as crude supernatant. However, when applied after purification, an additional band became more distinct. Since purified and Endo $\mathrm{H}_{\mathrm{f}}$ deglycosylated CUTAB1 only showed one band, the two different bands were assigned to the glycosylated and non-glycosylated enzyme (Koschorreck et al., 2010). In our case Thc_Cut1 appeared as a distinctive band around $38 \mathrm{kDa}$ (Figure $\mathbf{2 A}$, right), indicating its high level of glycosylation, whereas Endo $\mathrm{H}_{\mathrm{f}}$ deglycosylated Thc_Cut1 showed one clear band corresponding to the calculated mass of $29.4 \mathrm{kDa}$ (Figure 2A, left; Herrero Acero et al., 2011). The protein band around $70 \mathrm{kDa}$ corresponds to Endo $\mathrm{H}_{\mathrm{f}}$ used for deglycosylation. On the contrary, Thc_Cut1_ko mutants showed a clear band around $29 \mathrm{kDa}$ with or without Endo $\mathrm{H}_{\mathrm{f}}$ treatment suggesting that the glycosylation sites were successfully knocked out in both mutants (Figures 2B,C). These results were confirmed by staining SDS PAGE gels with Pro-Q ${ }^{\circledR}$ Emerald 300 glycoprotein stain, which creates a bright green-fluorescent signal on glycoproteins. For direct comparison of Commassieand Glyco-staining, the same samples were loaded on two SDS PAGE gels whereas only one gel was glycostained afterwards. Glycostained gels showed clearly fluorescent bands of purified native Thc_Cut1 expressed by P. pastoris, whereas no fluorescent bands were detected for Thc_Cut1 expressed by E. coli (Gamerith et al., in press; Figure 3) or for Endo $\mathrm{H}_{\mathrm{f}}$ deglycosylated Thc_Cut1 expressed by $P$. pastoris (see Figure S1).

Although all fermentation supernatant samples from different time points during expression of Thc_Cut1_ko mutants showed high unspecific fluorescent signals, no specific bands corresponding to Thc_Cut1 were detected, suggesting a high background noise of the medium (see Figure S2 for Thc_Cut1_ko_ST). Also purified glycosylation site knockout mutants did not show any fluorescent bands, verifying the successful knock out of all glycosylation sites (Figure S2, last lane for purified Thc_Cut1_ko_ST as example). Posttranslational glycosylation processes might have an influence on the expression level due to their time- and energy-demand. Furthermore, also dissolved oxygen concentrations and careful control of the methanol levels are crucial for a high expression of recombinant proteins in P. pastoris (Seman et al., 2014). Methanol might not only have toxic effects for the cells but, as a highly flammable and hazardous substance it is also problematic for large-scale applications (Ahmad et al., 2014). Nevertheless,

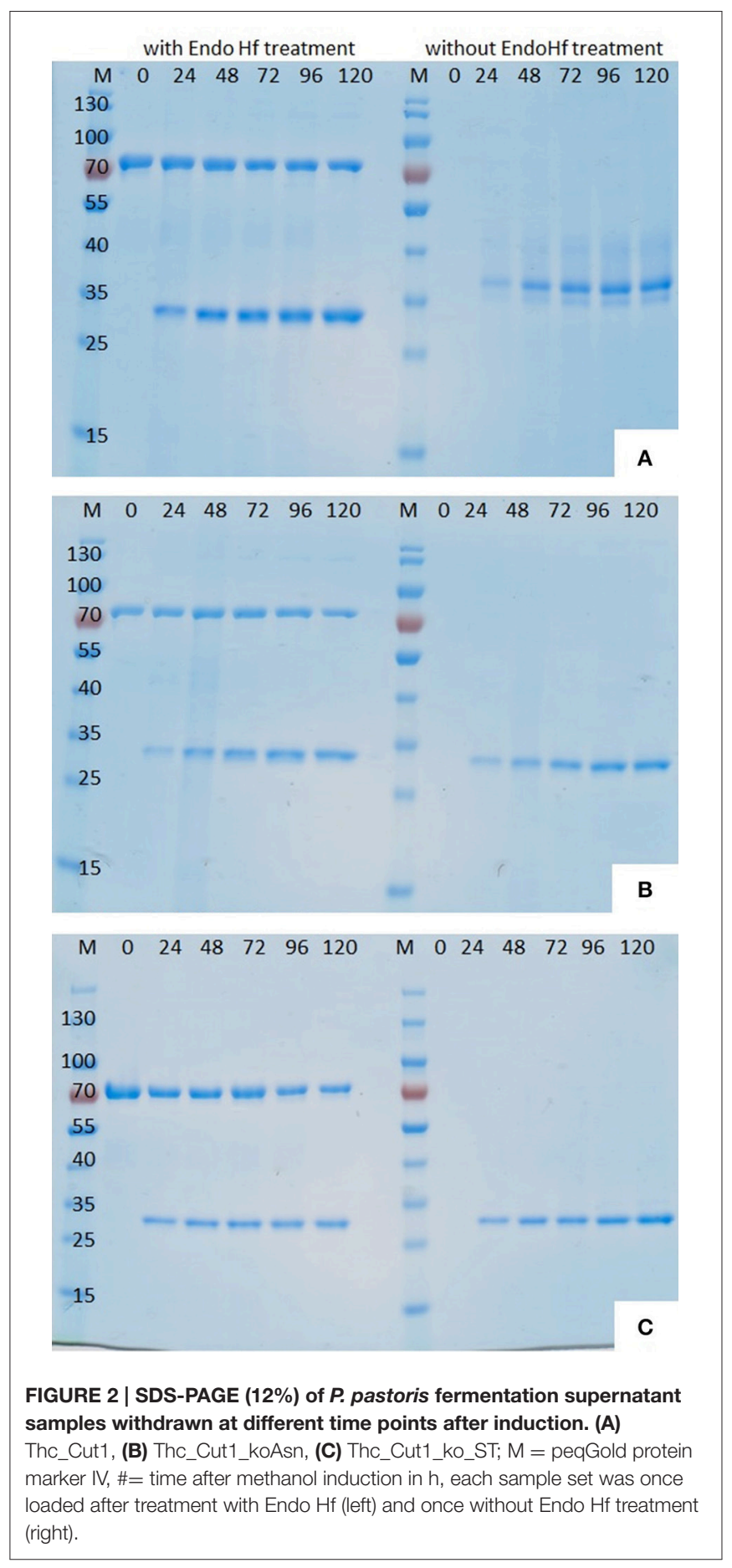

studies on methanol-inducible promoters, including AOX1, have shown that protein expression can also be achieved without methanol induction by constitutive co-expression of positively acting transcription factor Prm1p from either of the GAP, TEF, or PGK promoters (Takagi et al., 2012). In agreement with SDS-PAGE analysis also an increase of total extracellular protein concentration, determined by Bradford assay (BioRad) and (BSA) as standard, as well as an increase in volumetric esterase 


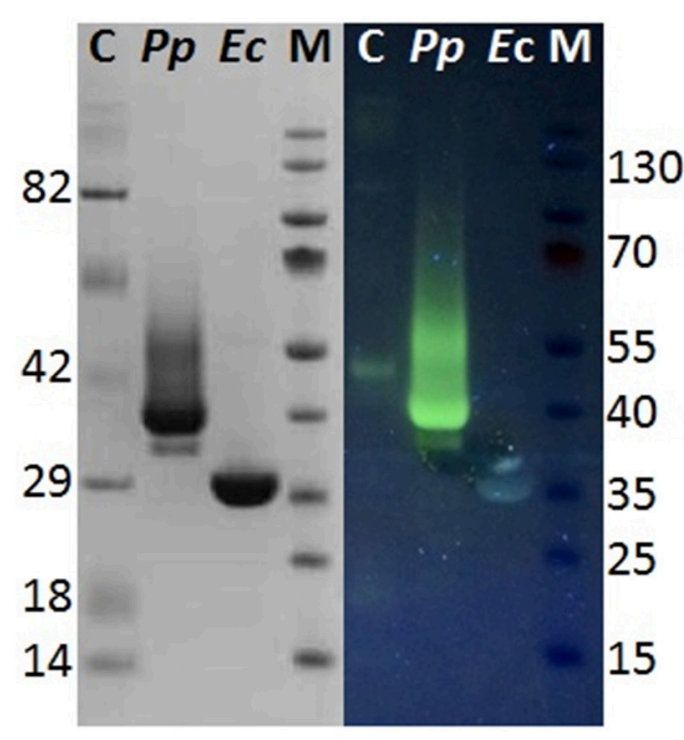

FIGURE 3 | Glycostain gel analysis of $\boldsymbol{P}$. pastoris and $\boldsymbol{E}$. coli expressed Thc_Cut1. Left, SDS PAGE gel; Right, Glycostained gel; same samples were applied on both gels; C, Candy cane protein marker; M, peqGold protein marker IV; Pp, P. pastoris expressed Thc_Cut1; Ec, E. coli expressed Thc_Cut1.

activity on $p \mathrm{NPB}$ as substrate was detected in fermentation supernatants over time (Figures 4A,B, respectively). Within $24 \mathrm{~h}$ from the methanol addition, induction resulted in a clear increase in the total extracellular protein concentration. Interestingly, no significant differences between the expression of native Thc_Cut1 and Thc_Cut1_ko mutants concerning the total extracellular protein concentration were observed. Furthermore, the volumetric activity of all enzyme variants on $p$ NPB was of the same order of magnitude.

Heterologous expression of Thc_Cut1 and Thc_Cut1_ko mutants in $P$. pastoris resulted in about $400 \pm 20 \mathrm{mg}$ total extracellular protein per liter in shaking flasks without optimization of culture conditions. These results are comparable to the previously reported expression level of $F$. solani cutinase in $P$. pastoris of $340 \mathrm{mg}$ extracellular protein per liter (Kwon et al., 2009). In comparison to heterologous expression of CUTAB1 in P. pastoris by Koschorreck et al., yielding in $212 \mathrm{mg}$ extracellular protein per liter, the expression level of Thc_Cut1 was almost doubled (Koschorreck et al., 2010). It is well-known that especially in the case of $P$. pastoris optimization of expression conditions in shake flasks or fed-batch fermenters can largely improve protein yields (Schilling et al., 2002; Zhao et al., 2008). However, the scope of this study was to demonstrate the general feasibility of Thc_Cut1 expression in P. pastoris.

\section{Immobilized Metal Ion Affinity Chromatography (IMAC) for Enzyme Purification}

From the $70 \mathrm{~mL}$ crude supernatants of each enzyme $65 \mathrm{~mL}$ were loaded onto HisTrap ${ }^{\mathrm{TM}}$ excel columns resulting in 14

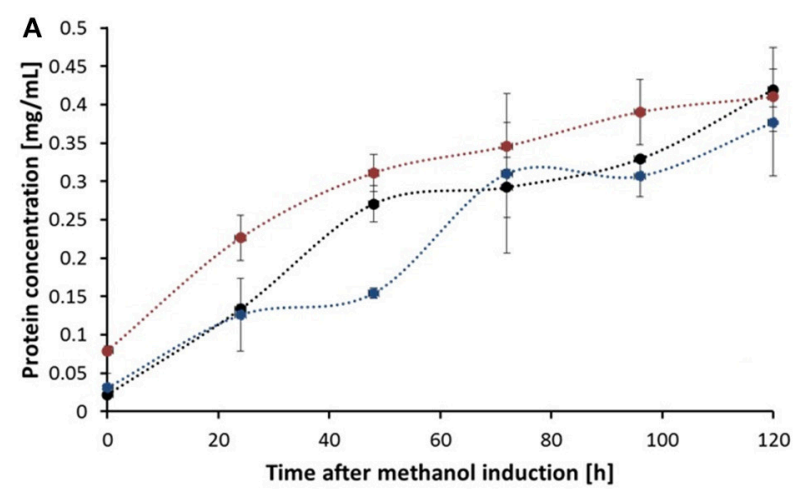

B

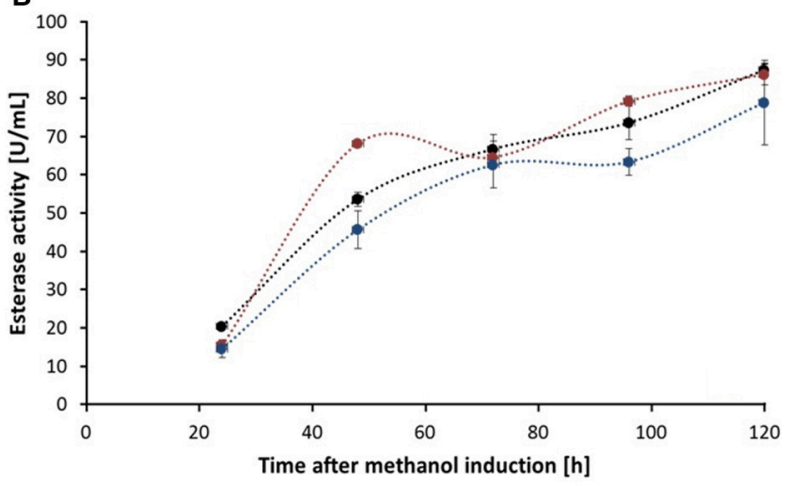

FIGURE 4 | Total protein concentration (A) and esterase activity (B) of fermentation supernatant samples of different time points after methanol induction. Thc_Cut1 (black line), Thc_Cut1_ko_Asn (blue line), and Thc_Cut1_ko_ST (red line). Time point $0 \mathrm{~h}$ indicates the start of methanol feed. Error bars show standard deviations of triplicate measurements.

$\mathrm{mL}$ of purified and buffer exchanged enzymes with different concentrations and esterase activities (Table 2). Interestingly, around $75 \%$ of the native Thc_Cut1 and Thc_Cut1_koST could be recovered from the crude supernatant, whereas only around $34 \%$ of Thc_Cut1_koAsn could be purified. Protein peaks of Thc_Cut1 and Thc_Cut1_ko were detected at $280 \mathrm{~nm}$ and the presence of enzymes in the corresponding fractions was confirmed by SDS-PAGE analysis (see Figure S3 for example of Thc_Cut1 purification).

Kwon et al. reported a negative effect of a C-terminal 6xHis tag on the cellular process for proper synthesis, folding, and secretion of F. solani cutinase in P. pastoris (Kwon et al., 2009). Similarly, also C-terminal fusion of small tags [such as FLAG-(Gly)5 and His-(Gly) 5 tags] to the extracellular domain of human Fas ligand (hFasLECD) led to a failure in secretion of functional protein in $P$. pastoris, whereas the secretion of functional hFasLE CD was retained upon N-terminal tagging (Muraki, 2006). Nonetheless, since all cutinases used in this study had a C-terminal 6xHis tag, it was not possible to assess any effect of $\mathrm{C}$-terminal tags within this study.

\section{Enzymatic Hydrolysis of Aromatic Polyesters (PET)}

Several cutinases (Vertommen et al., 2005; Heumann et al., 2006; Donelli et al., 2009; Kanelli et al., 2015)_including E. coli 
TABLE 2 | Production of various ThC-Cut1 variants in P. pastoris.

\begin{tabular}{|c|c|c|c|c|c|}
\hline Enzyme & Purification step & Total protein $(\mathrm{mg})^{\mathrm{a}}$ & Total activity $(\mathbf{U})^{\mathbf{b}}$ & Specific activity (U/mg) & Yield $(\%)^{c}$ \\
\hline \multirow[t]{2}{*}{ Thc_Cut1 } & Crude supernatant & 27 & 5,700 & 210 & 100 \\
\hline & Purified and buffer exchanged & 21 & 2,100 & 100 & 75 \\
\hline \multirow[t]{2}{*}{ Thc_Cut1_koAsn } & Crude supernatant & 25 & 5,100 & 210 & 100 \\
\hline & Purified and buffer exchanged & 8 & 1,432 & 170 & 34 \\
\hline \multirow[t]{2}{*}{ Thc_Cut1_koST } & Crude supernatant & 27 & 5,600 & 210 & 100 \\
\hline & Purified and buffer exchanged & 20 & 3,500 & 180 & 75 \\
\hline
\end{tabular}

aProtein concentration was determined as described in section Protein Analysis and calculated for total volume.

${ }^{b}$ Esterase activity was determined as described in section Esterase Activity Assay and calculated for total volume.

${ }^{c}$ Relative yield with protein content of crude supernatant set to $100 \%$.

expressed Thc_Cut1 (Herrero Acero et al., 2011)-have been found to hydrolyze PET. For this reason, this aromatic polyester was chosen as substrate for performing the first hydrolysis experiments with cutinases expressed in $P$. pastoris in order to confirm their activity. Besides the crystallinity of polyesters (Mochizuki and Hirmai, 1997; Vertommen et al., 2005; Herzog et al., 2006; Mueller, 2006; Brueckner et al., 2008; Tokiwa et al., 2009; Pellis et al., 2016a), also the incubation temperature is wellknown to affect the enzymatic hydrolysis of polyesters, mainly by affecting the polymer chain mobility (Marten et al., 2003; Eberl et al., 2009). Incubation temperatures close to the glass transition temperature $\left(T_{\mathrm{g}}\right)$ are suggested in order to promote enzymatic attack of polymers for degradation purposes (Mueller et al., 2005; Mueller, 2006; Kawai et al., 2014; Then et al., 2016) while $T<T_{\mathrm{g}}$ are instead suggested when the surface hydrophilization is desired (Pellis et al., 2015, in press; Ortner et al., 2017). We recently reported that, for short term reactions, higher incubation temperatures led to faster hydrolysis rates of PET by E. coli expressed Thc_Cut1 (Gamerith et al., in press) while for longer reaction times limited enzyme stability may counteract this effect. Furthermore, the ionic strength as well as the buffer choice were found to have a severe effect on enzymatic hydrolysis of PET by polyester hydrolases (Schmidt et al., 2016). High buffer concentrations might prevent the $\mathrm{pH}$ decrease of the incubating buffer during hydrolysis reactions due to the acidic released products (e.g., TPA). Hence, hydrolysis of a $24 \%$ crystalline PET powder with $P$. pastoris expressed Thc_Cut1, Thc_Cut1_ko_Asn and Thc_Cut1_ko_ST were performed at $65^{\circ} \mathrm{C}$ in $1 \mathrm{M} \mathrm{KH}_{2} \mathrm{PO}_{4} / \mathrm{K}_{2} \mathrm{HPO}_{4} \mathrm{pH} 8.0$ and released products were quantified by HPLC-DAD (Figure 5). No significant differences between the hydrolysis efficiency of the two glycosylation site knock out mutants could be observed, but treatment with the knock out mutants resulted in slightly increased TPA levels compared to the native Thc_Cut1. $\mathrm{Up}$ to $62 \mathrm{mM}$ released TPA were observed after $96 \mathrm{~h}$ of hydrolysis, corresponding to $\sim 24 \%$ degradation of initial PET powder to soluble TPA. Compared to previously reported results for PET hydrolysis with Thc_Cut1 by Gamerith et al.using incubation conditions of $100 \mathrm{mM} \mathrm{KH} \mathrm{PO}_{4} / \mathrm{K}_{2} \mathrm{HPO}_{4} \mathrm{pH}$ 7.0 and $60^{\circ} \mathrm{C}$ (Gamerith et al., in press) - a combination of increased incubation temperature, higher $\mathrm{pH}$ and increased buffer concentration resulted in significantly higher hydrolysis rates of PET by Thc_Cut1 in this current study. This high degree of hydrolysis signifies a big step toward feasibility of enzymatic recycling of polyesters.

It is interesting to note that while the two glycosylation site knock out mutants showed very similar results with regards to both expression as well as PET hydrolysis rates, the purification yields of purified Thc_Cut1_ko_Asn were significantly lower compared to Thc_Cut1_ko_ST. Due to the highest productivity (and therefore scalability) for the expression, further enzyme selectivity studies on aliphatic polyesters were performed using the native Thc_Cut1 and Thc_Cut1_koST.

\section{Enzymatic Hydrolysis of Aliphatic Polyesters (PHBV and PBS)}

In order to investigate the substrate specificities of Thc_Cut1 and Thc_Cut1_koST in more detail, hydrolysis experiments were performed using the aliphatic polyesters PHBV and PBS as substrates. Both aliphatic polyesters were successfully hydrolyzed by Thc_Cut1 and Thc_Cut1_koST, although to very different extents. Figures 6, 7 show the quantified concentrations of released products after up to $96 \mathrm{~h}$ enzymatic hydrolysis of $\mathrm{PHBV}$ and PBS powders, respectively. Interestingly, Thc_Cut1 and Thc_Cut1_koST reached similar levels of released 3-HBA $(\sim 0.5$ $\mathrm{mM}$ ) for the hydrolysis of PBHV, whereas for PBS, the released products were approximately twice as high for Thc_Cut1_koST as compared to native Thc_Cut1 (i.e., $\sim 14$ vs. $\sim 7 \mathrm{mM} \mathrm{SA}$ and $\mathrm{BDO}$ ). Due to different substrate concentrations (50 mg for PET vs. $5 \mathrm{mg}$ for PBS and PHBV) the absolute values of released products seem lower compared to PET hydrolysis, but in fact the quantified SA and BDO concentrations correspond to $\sim 24$ and $48 \%$ degradation of initial PBS powder to soluble released products by Thc_Cut1 and Thc_Cut1_koST, respectively. This finding indicates that there was a remarkable influence of the glycosylation on the substrate specificity. Glycosylation may not only lead to increased stability and protection against proteolysis, but may also have a role on the catalytic activity. For several proteases it has been reported that glycosylation can alter their substrate recognition, their specificity and binding affinity, as well as the turnover rates. Moreover, glycans which are in the vicinity of the active site are more likely to influence the substrate binding (Goettig, 2016). Recently, we have demonstrated that both surface engineering as well as attachment of polymer binding modules or hydrophobins can dramatically influence 


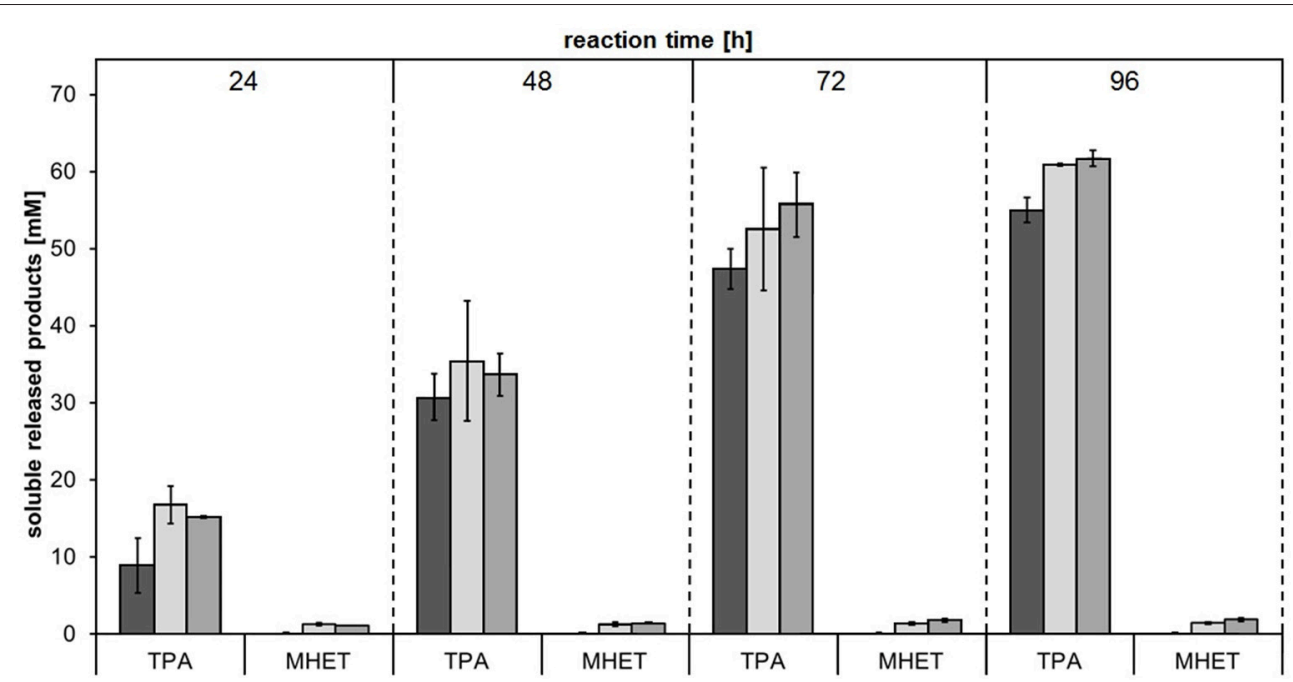

FIGURE 5 | Concentrations of soluble released products terephthalic acid (TPA) and mono(2-hydroxyethyl) terephthalate (MHET) upon enzymatic hydrolysis of PET powder by Thc_Cut1 (dark gray bars), Thc_Cut1_ko_Asn (light gray bars) and Thc_Cut1_ko_ST (middle gray bars). Time scan for 24, 48, 72, or $96 \mathrm{~h}$ was performed at $65^{\circ} \mathrm{C}$ with $5 \mu \mathrm{M}$ enzyme in $1 \mathrm{M} \mathrm{KPi} \mathrm{pH} 8.0$ with $50 \mathrm{mg} / \mathrm{mL}$ substrate at $100 \mathrm{rpm}$.

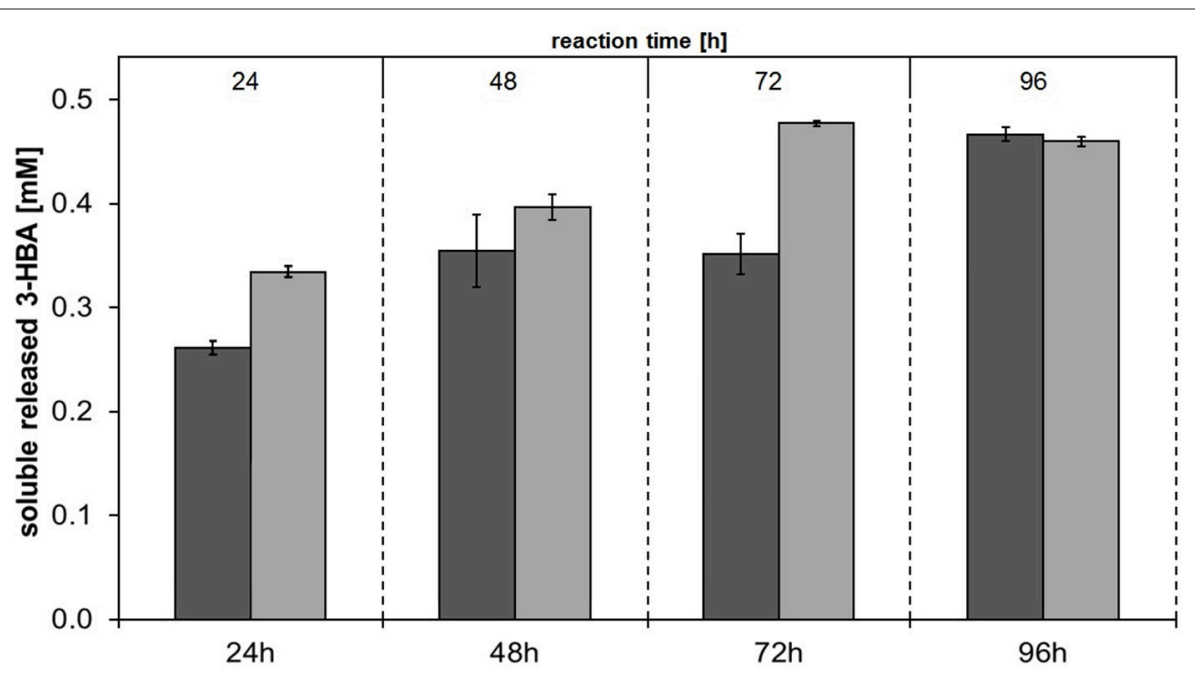

FIGURE 6 | Concentrations of soluble released 3-hydroxybutyric acid (3-HBA) upon enzymatic hydrolysis of PHBV powder by Thc_Cut1 (dark gray bars) and Thc_Cut1_ko_ST (middle gray bars). Time scan for 24, 48, 72, or $96 \mathrm{~h}$ was performed at $65^{\circ} \mathrm{C}$ with $5 \mu \mathrm{M}$ enzyme in $1 \mathrm{M} \mathrm{KPi} \mathrm{pH} 8.0$ with $5 \mathrm{mg} / \mathrm{mL}$ substrate at $100 \mathrm{rpm}$.

sorption and thereby hydrolysis of polyesters (Herrero Acero et al., 2013; Ribitsch et al., 2013, 2015).

To support faster Thc_Cut1-mediated hydrolysis of PBS than PHBV, we complemented the data above by QCM measurements. Previous studies showed that QCM can be used to study both adsorption of enzymes to the polyester surface and mass loss of polyester films due to enzymatic hydrolysis in real time (Ribitsch et al., 2013; Perz et al., 2015; Zumstein et al., 2016). Here, we monitored the mass change of spin-coated PBS and PBHV films during their hydrolysis by Thc_Cut1 (Figure 8). These measurements showed that the mass of the spin-coated
PBS films rapidly decreased after the addition of Thc_Cut1 and that the adlayer mass reached stable final values within $1.5 \mathrm{~h}$ of the onset of Thc_Cut1 addition (Figure 8A; results of duplicate experiments). When Thc_Cut1 was added to PHBV films, we measured an initial adlayer mass increase that we ascribed to the adsorption of Thc_Cut1 to the film surface. Detection of this mass increase implies that PHBV hydrolysis was slow (in contrast to PBS). Slow PHBV hydrolysis was substantiated by the finding of slow and continuous decreases in the PHBV film mass over the subsequent hours of continuous exposure to Thc_Cut1 (Figure 8B). The differences in the mass decreases determined 


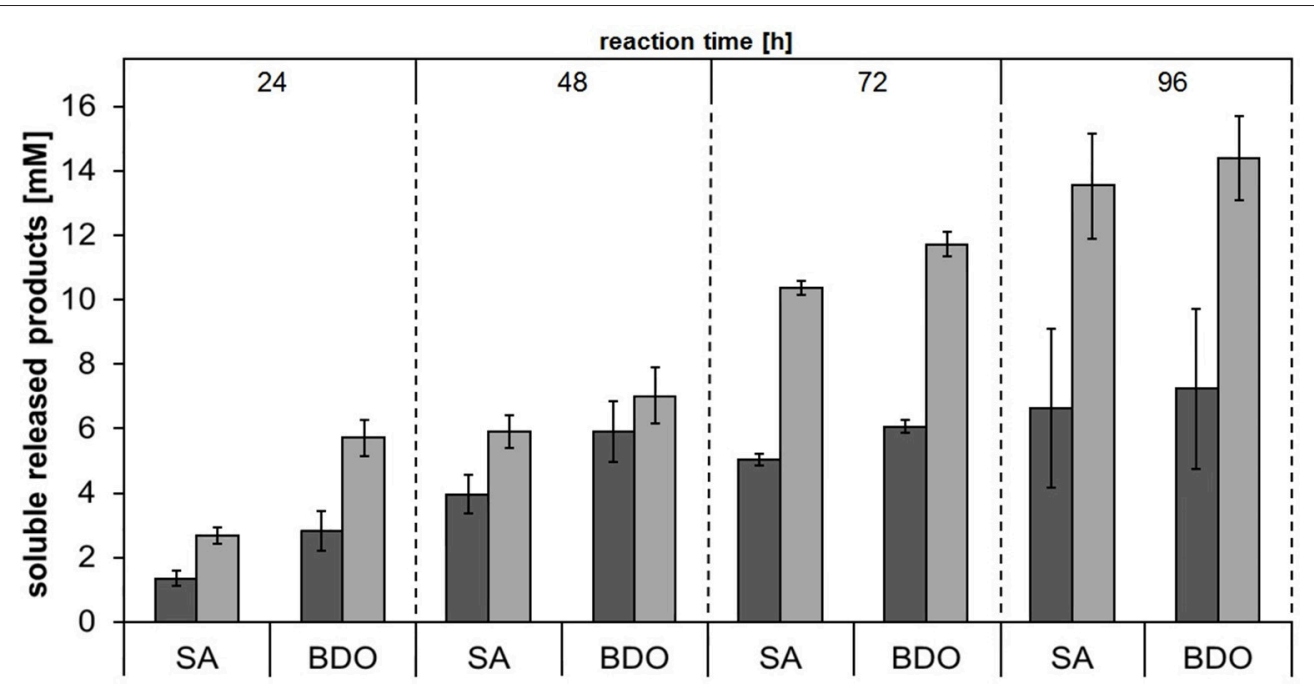

FIGURE 7 | Concentrations of soluble released products succinic acid (SA) and 1,4-butanediol (BDO) upon enzymatic hydrolysis of PBS powder by Thc_Cut1 (dark gray bars) and Thc_Cut1_ko_ST (middle gray bars). Time scan for $24,48,72$ or $96 \mathrm{~h}$ was performed at $65^{\circ} \mathrm{C}$ with $5 \mu \mathrm{M}$ enzyme in $1 \mathrm{M} \mathrm{KPi} \mathrm{pH}$ 8.0 with $5 \mathrm{mg} / \mathrm{mL}$ substrate at $100 \mathrm{rpm}$.
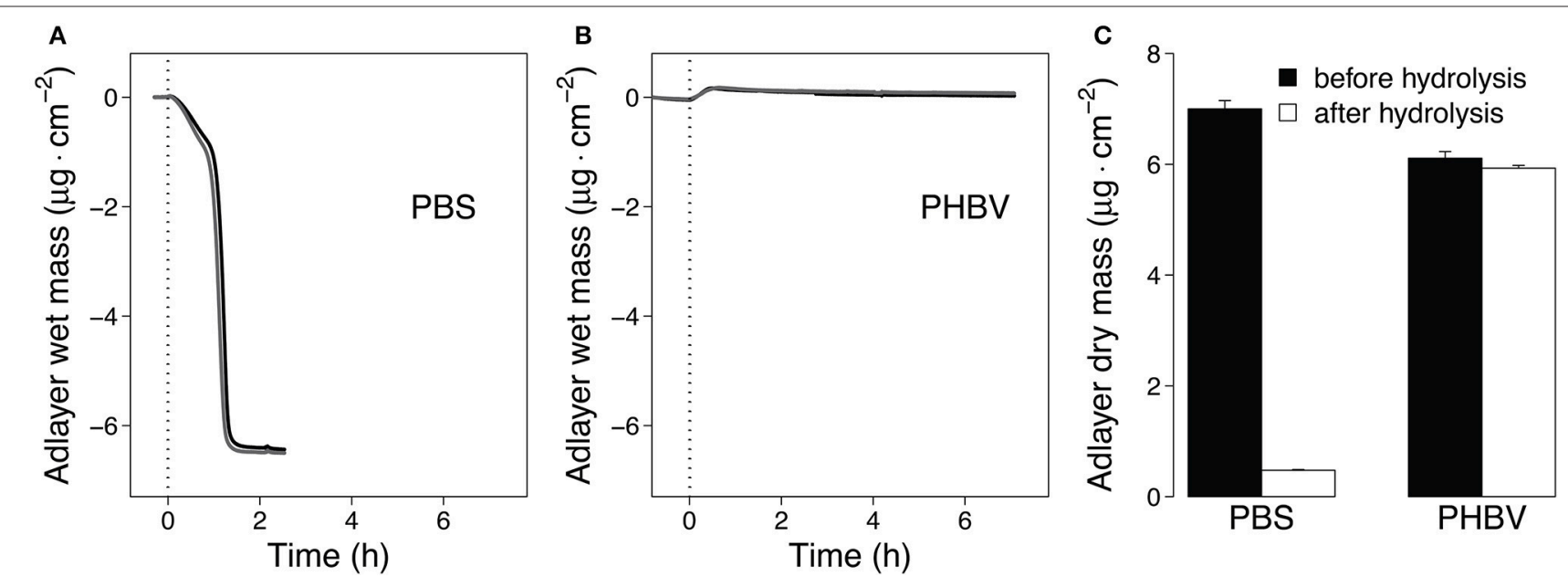

FIGURE 8 | Quartz Crystal Microbalance (QCM) measurements of hydrolysis of spin-coated PBS and PHBV films by Thc_cut1. (A,B). Progress curves of the polyester adlayer mass coated onto the QCM sensors during the hydrolysis of PBS (A) and PHBV (B). At time $t=0 \mathrm{~h}$ we added Thc_cut1 to the buffer running over the films, as indicated by the vertical dashed lines in panels $(\mathbf{A}, \mathbf{B})$. Black and gray lines represent duplicate experiments (C). Dry masses of the sensor adlayers before and after the hydrolysis experiments. Hydrolysis experiments were performed at $40^{\circ} \mathrm{C}$ and $\mathrm{pH} 7.0(3 \mathrm{mM}$ Tris buffer).

in the QCM-D measurements were consistent with the changes in the dry masses of the sensors, which we determined by measuring the adlayer masses of dried sensors before and after spin coating step and after the enzymatic hydrolysis experiment. These measurements revealed that 93 and $3 \%$ of the spincoated PBS and PHBV masses, respectively, were removed during the hydrolysis experiments. We note that the Thc_Cut1 that was used for the QCM experiments was expressed in E. coli. This Thc_Cutl variant is expected to have no glycosylation and to therefore show the same activity on polyesters as the Thc_Cut1_ko_ST variant that was expressed in P. pastoris, for which we showed the absence of glycosylation (Figure S2). In summary, the QCM-based analysis supported faster hydrolysis of PBS than PBHV by Thc_Cut1.

Among the tested polyesters, PBS was most extensively hydrolyzed and was therefore chosen for additional analyses. Hydrolysis of PBS films followed by weight loss and SEM analysis were performed. The concentrations of released products from PBS films showed the same trend as for PBS powderThc_Cut1_koST released more than double the amount of hydrolysis products compared to native Thc_Cut1 $(\sim 48-50 \mathrm{mM}$ SA and BDO by Thc_Cut1_koST vs. $\sim 12-15 \mathrm{mM} \mathrm{SA}$ and BDO by Thc_Cut1) (Figure 9 and Figure S4). These results are in accordance with the weight loss, which reached up to 


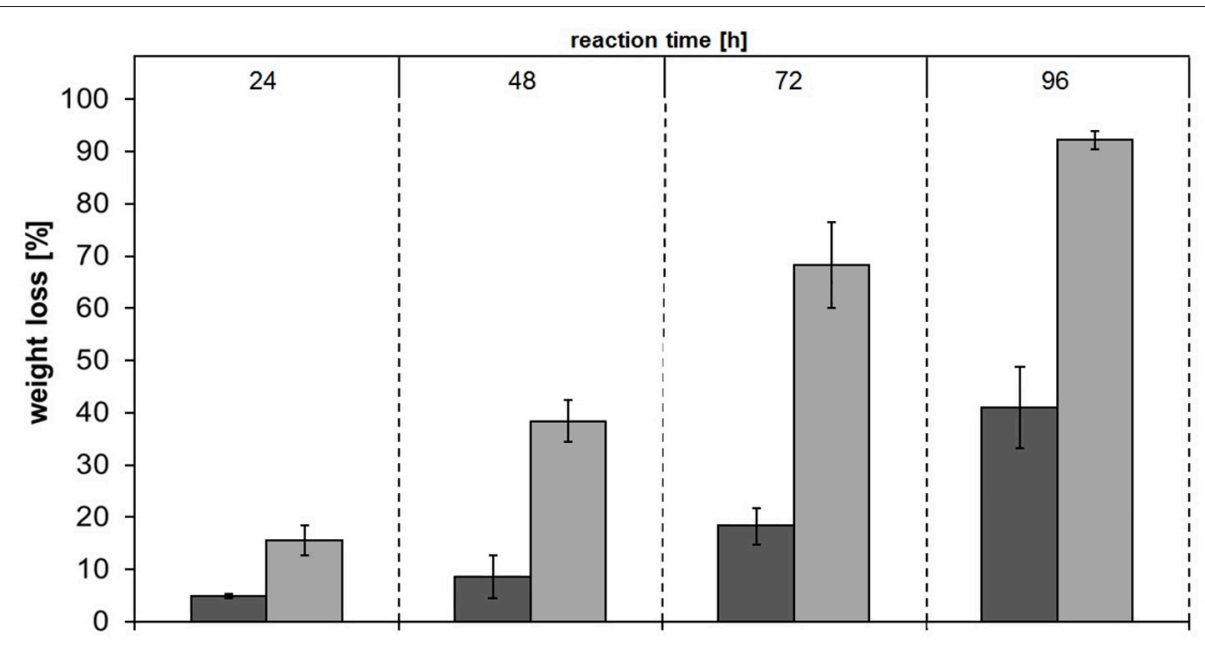

FIGURE 9 | Weight loss of PBS films upon enzymatic hydrolysis by Thc_Cut1 (dark gray bars) and Thc_Cut1_ko_ST (middle gray bars). Time scan for 24, 48,72 , or $96 \mathrm{~h}$ was performed at $65^{\circ} \mathrm{C}$ with $5 \mu \mathrm{M}$ enzyme in $1 \mathrm{M} \mathrm{KPi} \mathrm{pH} 8.0$ with $0.5 \times 1.0 \mathrm{~cm}$ PBS films at $100 \mathrm{rpm}$

92\% with Thc_Cut1_koST and only around 41\% with Thc_Cut1 within 96 h (see Figure 9). Hu et al. recently reported on complete degradation of PBS films by a recombinant cutinase from Fusarium solani within $6 \mathrm{~h}$ (Hu et al., 2016).

To complement the PBS hydrolysis data, an additional SEM characterization of the film surfaces was performed. Figure 10 shows clear changes in the morphology of PBS film surfaces caused by treatments with both native Thc_Cut1 and Thc_Cut1_koST (Figures 10C-F), while no detectable changes of the control samples occured (Figures 10A,B). Moreover, 24 $\mathrm{h}$ of enzymatic hydrolysis of the PBS films surface resulted in more surface erosion when using the ko mutant than the native Thc_Cut1 (Figure 10C vs. Figure 10E). After 96 h, the formation of "holes" throughout the polymeric sample is visible for the ko mutant (Figure 10F) while only an increased surface roughness was observed for the Thc_Cut1 treatment (Figure 10D).

\section{CONCLUSIONS}

In this study, we demonstrated the general feasibility of expressing Thc_Cut1 and two glycosylation site knock out mutants, Thc_Cut1_koAsn and Thc_Cut1_koST, in P. pastoris. Furthermore, we have shown that Thc_Cut1 and Thc_Cut1_ko mutants hydrolyze aromatic (PET) and aliphatic (PHBV and PBS) polyester powders, although at very different rates as shown by HPLC quantification of released products. These findings were also confirmed by QCM measurements, which showed a 3.0\% mass change for PHBV thin films and a $93.2 \%$ mass decrease for PBS thin films upon enzymatic hydrolysis with Thc_Cut1. The finding that treatment of PBS films with Thc_Cut1 and Thc_Cut1_koST resulted in large PBS weight losses and clear effects on film surface topography imaged by SEM confirm the potential of Thc_Cut1 and mutants for degradation of PBS films. Together with the high activity of

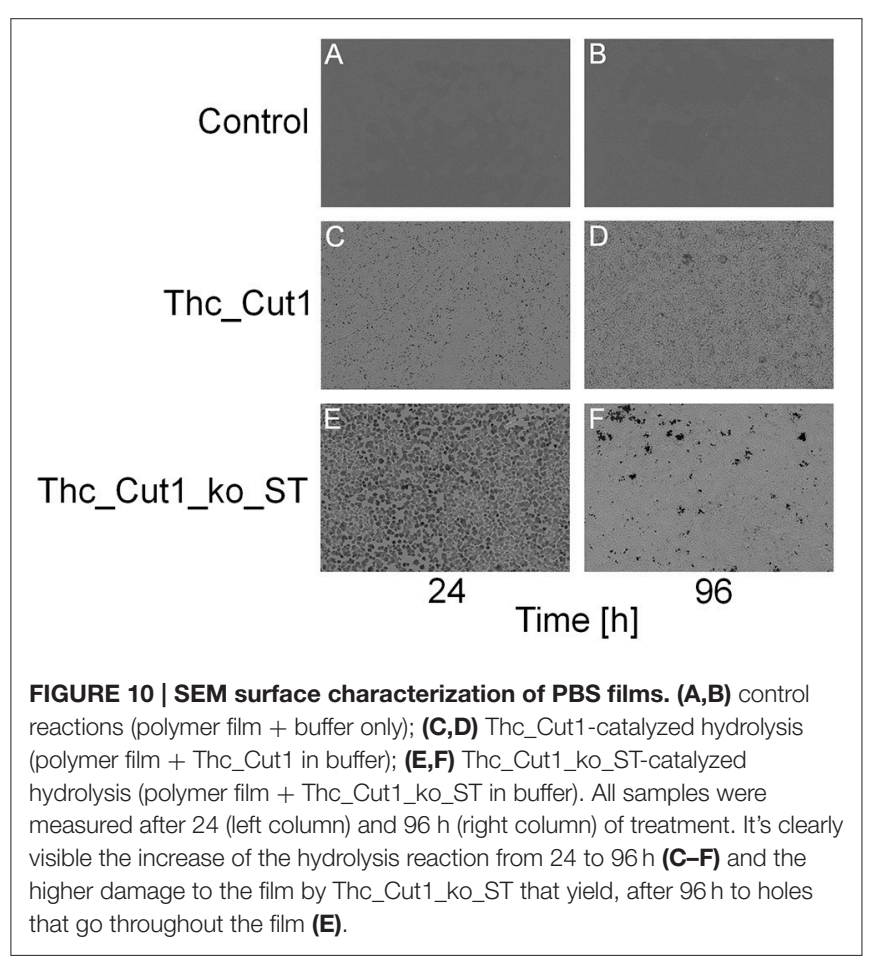

Thc_Cut1 and Thc_Cut1_ko mutants on PET, this study provides a significant contribution toward enzymatic degradation of polyesters.

\section{AUTHOR CONTRIBUTIONS}

CG, SG, and SZ expressed and purified the enzymes. DR designed the mutants. CG performed the PET hydrolysis experiments. MZ and MS conducted the QCM hydrolysis experiments and wrote the related sections of the manuscript. MV and AP performed 
the aliphatic polyesters hydrolysis of powders and films and the relative SEM images. CG, AP, EH, and GG wrote the manuscript.

\section{ACKNOWLEDGMENTS}

This work has been supported by CARBIOS company (SaintBeauzire, France), the Federal Ministry of Science, Research, and Economy (BMWFW), the Federal Ministry of Traffic, Innovation, and Technology (bmvit), the Styrian Business Promotion Agency SFG, the Standortagentur Tirol and

\section{REFERENCES}

Ahmad, M., Hirz, M., Pichler, H., and Schwab, H. (2014). Protein expression in Pichia pastoris: recent achievements and perspectives for heterologous protein production. Appl. Microbiol. Biotechnol. 98, 5301-5317. doi: 10.1007/s00253-014-5732-5

Bollok, M., Resina, D., Valero, F., and Ferrer, P. (2009). Recent patents on the Pichia pastoris expression system: expanding the toolbox for recombinant protein production. Recent Pat. Biotechnol. 3, 192-201. doi: $10.2174 / 187220809789389126$

Bretthauer, R. K., and Castellino, F. J. (1999). Glycosylation of Pichia pastorisderived proteins. Biotechnol. Appl. Biochem. 30(Pt 3), 193-200.

Brueckner, T., Eberl, A., Heumann, S., Rabe, M., and Guebitz, M. G. (2008). Enzymatic and chemical hydrolysis of poly(ethylene terephthalate) fabrics. Polym. Chem. 46, 6435-6443. doi: 10.1002/pola.22952

Cereghino, J. L., and Cregg, J. M. (2000). Heterologous protein expression in the methylotrophic yeast Pichia pastoris. FEMS Microbiol. Rev. 24, 45-66. doi: 10.1111/j.1574-6976.2000.tb00532.x

Clark, J. H., Farmer, T. J., Herrero-Davila, L., and Sherwood, J. (2016). Circular economy design considerations for research and process development in the chemical sciences. Green Chem. 18, 3914-3934. doi: 10.1039/C6GC0 0501B

Cregg, J. M., Vedvick, T. S., and Raschke, W. C. (1993). Recent advances in the expression of foreign genes in Pichia pastoris. Biotechnology 11, 905-910. doi: 10.1038/nbt0893-905

Donelli, I., Taddei, P., Smet, P. F., Poelman, D., Nierstrasz, V. A., and Freddi, G. (2009). Enzymatic surface modification and functionalization of PET: a water contact angle, FTIR, and fluorescence spectroscopy study. Biotechnol. Bioeng. 103, 845-856. doi: 10.1002/bit.22316

Eberl, A., Heumann, S., Bruckner, T., Araujo, R., Cavaco-Paulo, A., Kaufmann, F., et al. (2009). Enzymatic surface hydrolysis of poly(ethylene terephthalate) and bis(benzoyloxyethyl) terephthalate by lipase and cutinase in the presence of surface active molecules. J. Biotechnol. 143, 207-212. doi: 10.1016/j.jbiotec.2009.07.008

Eriksen, M. L., Lebreton, C. M., Carson, H. S., Thiel, M., Moore, C. J., Reisser, J. et al. (2014). Plastic pollution in the world's oceans: more than 5 trillion plastic pieces weighing over 250,000 tons afloat at sea. PLOS ONE 9:e111913. doi: 10.1371/journal.pone.0111913

Gamerith, C., Herrero Acero, E., Pellis, A., Vielnasche, R., Luschnig, D., Zartl, B., et al. (2016). Improving enzymatic polyurethane hydrolysis by tuning enzyme sorption. Polym. Degrad. Stabili. 132, 69-77. doi: 10.1016/j.polymdegradstab.2016.02.025

Gamerith, C., Zartl, B., Pellis, A., Guillamot, F., Marty, A., Herrero Acero, E., et al. (in press). Enzymatic recovery of polyester building blocks from polymer blends. Process Biochem. doi: 10.1016/j.procbio.2017.01.004

Goettig, P. (2016). Effects of glycosylation on the enzymatic activity and mechanisms of proteases. Int. J. Mol. Sci. 17, 1969. doi: 10.3390/ijms171 21969

Grinna, L. S., and Tschopp, J. F. (1989). Size distribution and general structural features of $\mathrm{N}$-linked oligosaccharides from the methylotrophic yeast, Pichia pastoris. Yeast 5, 107-115. doi: 10.1002/yea.3200 50206
ZIT-Technology Agency of the City of Vienna through the COMET-Funding Program managed by the Austrian Research Promotion Agency FFG. The authors thank Mr. Ghagik Ghazaryan from ETH Zurich for the DSC analysis.

\section{SUPPLEMENTARY MATERIAL}

The Supplementary Material for this article can be found online at: http://journal.frontiersin.org/article/10.3389/fmicb. 2017.00938/full\#supplementary-material

Harmsen, F. H. P., Hackmann, M. M., and Bos, H. L. (2014). Green building blocks for bio-based plastics. Biofuels Bioproducts Biorefining 8, 306-324. doi: 10.1002/bbb.1468

Herrero Acero, E., Ribitsch, D., Dellacher, A., Zitzenbacher, S., Marold, A., Steinkellner, G., et al. (2013). Surface engineering of a cutinase from Thermobifida cellulosilytica for improved polyester hydrolysis. Biotechnol. Bioeng. 110, 2581-2590. doi: 10.1002/bit.24930

Herrero Acero, E., Ribitsch, D., Steinkellner, G., Gruber, K., Greimel, K., Eiteljoerg, I., et al. (2011). Enzymatic surface hydrolysis of PET: effect of structural diversity on kinetic properties of cutinases from thermobifida. Macromolecules 44, 4632-4640. doi: 10.1021/ma200949p

Herzog, K., Mueller, R. J., and Deckwer, W. D. (2006). Mechanism and kinetics of the enzymatic hydrolysis of polyester nanoparticles by lipases. Polym. Degrad. Stabili. 91, 2486-2498. doi: 10.1016/j.polymdegradstab.2006. 03.005

Heumann, S., Eberl, A., Pobeheim, H., Liebminger, S., Fischer-Colbrie, G., Almansa, E., et al. (2006). New model substrates for enzymes hydrolysing polyethyleneterephthalate and polyamide fibers. J. Biochem. Biophys. Methods 69, 89-99. doi: 10.1016/j.jbbm.2006.02.005

Hu, X., Gao, Z., Wang, Z., Su, T., Yang, L., and Li, P. (2016). Enzymatic degradation of poly(butylene succinate) by cutinase cloned from Fusarium solani. Polym. Degrad. Stabili. 134, 211-219. doi: 10.1016/j.polymdegradstab.2016. 10.012

Johnson, S. K., Zhang, W., Smith, L. A., Hywood-Potter, K. J., Todd Swanson, S., Schlegel, V. L., et al. (2003). Scale-up of the fermentation and purification of the recombinant heavy chain fragment $\mathrm{C}$ of botulinum neurotoxin serotype F, expressed in Pichia pastoris. Protein Expr. Purif. 32, 1-9. doi: 10.1016/j.pep.2003.07.003

Kanelli, M., Vasilakos, S., Nikolaivits, E., Ladas, S., Christakopoulos, P., and Topakas, E. (2015). Surface modification of poly(ethylene terephthalate) (PET) fibers by a cutinase from Fusarium oxysporum. Process Biochem. 50, 1885-1892. doi: $10.1016 /$ j.procbio.2015.08.013

Kawai, F., Oda, M., Tamashiro, T., Waku, T., Tanaka, N., Yamamoto, M., et al. (2014). A novel Ca2+-activated, thermostabilized polyesterase capable of hydrolyzing polyethylene terephthalate from Saccharomonospora viridis AHK190. Appl. Microbiol. Biotechnol. 98, 10053-10064. doi: 10.1007/s00253-014-5860-y

Koitabashi, M., Noguchi, M. T., Sameshima-Yamashita, Y., Hiradate, S., Suzuki, K., Yoshida, S., et al. (2012). Degradation of biodegradable plastic mulch films in soil environment by phylloplane fungi isolated from gramineous plants. $A M B$ Express 2:40. doi: 10.1186/2191-0855-2-40

Koschorreck, K., Liu, D., Kazenwadel, C., Schmid, R. D., and Hauer, B. (2010). Heterologous expression, characterization and site-directed mutagenesis of cutinase CUTAB1 from Alternaria brassicicola. Appl. Microbiol. Biotechnol. 87, 991-997. doi: 10.1007/s00253-010-2533-3

Kwon, M.-A., Kim, H. S., Yang, T. Y., Song, B. K., and Song, J. K. (2009). High-level expression and characterization of Fusarium solani cutinase in Pichia pastoris. Protein Expr. Purif. 68, 104-109. doi: 10.1016/j.pep.2009. 06.021

Laemmli, U. K. (1970). Cleavage of structural proteins during the assembly of the head of bacteriophage T4. Nature 227, 680-685. doi: 10.1038/227 $680 \mathrm{a} 0$ 
Lechner, A., Keckeis, H., Lumesberger-Loisl, F., Zens, B., Krusch, R., Tritthart, M., et al. (2014). The danube so colourful: a potpourri of plastic litter outnumbers fish larvae in Europe's second largest river. Environ. Pollut. 188, 177-181. doi: 10.1016/j.envpol.2014.02.006

Liu, Y., Xie, W., and Yu, H. (2014). Enhanced activity of Rhizomucor miehei lipase by deglycosylation of its propeptide in Pichia pastoris. Curr. Microbiol. 68, 186-191. doi: 10.1007/s00284-013-0460-0

Marten, E., Mueller, R.-J., and Deckwer, W.-D. (2003). Studies on the enzymatic hydrolysis of polyesters I. Low molecular mass model esters and aliphatic polyesters. Polym. Degrad. Stabili. 80, 485-501. doi: 10.1016/S0141-3910(03)00032-6

Marx, H., Mecklenbräuker, A., Gasser, B., Sauer, M., and Mattanovich, D. (2009). Directed gene copy number amplification in Pichia pastoris by vector integration into the ribosomal DNA locus. FEMS Yeast Res. 9, 1260-1270. doi: 10.1111/j.1567-1364.2009.00561.x

Mochizuki, M., and Hirmai, M. (1997). Structural effects on the biodegradation of aliphatic polyesters. Polym. Adv. Technol. 8, 203-209.

Mueller, R.-J. (2006). Biological degradation of synthetic polyesters-Enzymes as potential catalysts for polyester recycling. Process Biochem. 41, 2124-2128. doi: 10.1016/j.procbio.2006.05.018

Mueller, R.-J., Schrader, H., Profe, J., Dresler, K. W., Deckwer, D. (2005). Enzymatic degradation of poly(ethylene terephthalate): rapid hydrolyse using a hydrolase from T. fusca. Macromol. Rapid Comm. 26, 1400-1405. doi: $10.1002 /$ marc. 200500410

Muraki, M. (2006). Secretory expression of synthetic human Fas ligand extracellular domain gene in Pichia pastoris: influences of tag addition and Nglycosylation site deletion, and development of a purification method. Protein Expr. Purif. 50, 137-146. doi: 10.1016/j.pep.2006.08.006

Öberg, F., Sjöhamn, J., Fischer, G., Moberg, A., Pedersen, A., Neutze, R., et al. (2011). Glycosylation increases the thermostability of human aquaporin 10 protein. J. Biol. Chem. 286, 31915-31923. doi: 10.1074/jbc.M111.242677

Ortner, A., Pellis, A., Gamerith, C., Orcal Yebra, A., Scaini, D., Kaluzna, I., et al. (2017). Superhydrophobic functionalization of cutinase activated poly(lactic acid) surfaces. Green Chem. 19, 816-822. doi: 10.1039/C6GC03150A

Pellis, A., Gamerith, C., Ghazaryan, G., Ortner, A., Herrero Acero, E., and Guebitz, G. M. (2016a). Ultrasound-enhanced enzymatic hydrolysis of poly(ethylene terephthalate). Bioresour. Technol. 218, 1298-1302. doi: 10.1016/j.biortech.2016.07.106

Pellis, A., Haernvall, K., Pichlerc, C. M., Ghazaryand, G., Breinbauerc, R., and Guebitz, G. M. (2016b). Enzymatic hydrolysis of poly(ethylene furanoate). J. Biotechnol. 235, 47-53. doi: 10.1016/j.jbiotec.2016.02.006

Pellis, A., Herrero Acero, E., Ferrario, V., Ribitsch, D., Guebitz, G. M., and Gardossi, L. (2016c). The closure of the cycle: enzymatic synthesis and functionalization of bio-based polyesters. Trends Biotechnol. 34, 316-328. doi: 10.1016/j.tibtech.2015.12.009

Pellis, A., Herrero Acero, E., Gardossi, L., Ferrario, V., and Guebitz, G. M. (2016d). Renewable building blocks for sustainable polyesters: new biotechnological routes for greener plastics. Polymer Int. 65, 861-871. doi: 10.1002/ pi. 5087

Pellis, A., Herrero Acero, E., Weber, H., Obersriebnig, M., Breinbauer, R., Srebotnik, E., et al. (2015). Biocatalyzed approach for the surface functionalization of poly(L-lactic acid) films using hydrolytic enzymes. Biotechnol. J. 10, 1739-1749. doi: 10.1002/biot.201500074

Pellis, A., Silvestrini, L., Scaini, D., Coburn, J. M., Gardossi, L., Kaplan, D. L., et al. (in press). Enzyme-catalyzed functionalization of poly(L-lactic acid) for drug delivery applications. Process Biochem. doi: 10.1016/j.procbio.2016. 10.014

Perz, V., Zumstein, M. T., Sander, M., Zitzenbacher, S., Ribitsch, D., and Guebitz, G. M. (2015). Biomimetic approach to enhance enzymatic hydrolysis of the synthetic polyester poly(1,4-butylene adipate): fusing binding modules to esterases. Biomacromolecules 16, 3889-3896. doi: 10.1021/acs.biomac.5b01219

Pinazo, J. M., Domine, M. E., Parvulescu, V., and Petru, F. (2015). Sustainability metrics for succinic acid production: a comparison between biomass-based and petrochemical routes. Catalysis Today 239, 17-24. doi: 10.1016/j.cattod.2014.05.035

Ribitsch, D., Herrero Acero, E., Greimel, K., Dellacher, A., Zitzenbacher, S., Marold, A., et al. (2012). A new esterase from Thermobifida halotolerans hydrolyses PET and PLA. Polymers 4, 617-629. doi: 10.3390/polym4010617
Ribitsch, D., Herrero Acero, E., Przylucka, A., Zitzenbacher, S., Marold, A., Gamerith, C., et al. (2015). Enhanced cutinase-catalyzed hydrolysis of polyethylene terephthalate by covalent fusion to hydrophobins. Appl. Environ. Microbiol. 81, 3586-3592. doi: 10.1128/AEM.04111-14

Ribitsch, D., Heumann, S., Trotscha, E., Herrero Acero, E., Greimel, K., Leber, R., et al. (2011). Hydrolysis of polyethyleneterephthalate by paranitrobenzylesterase from Bacillus subtilis. Biotechnol. Progress 27, 951-960. doi: 10.1002/btpr.610

Ribitsch, D., Yebra, A. O., Zitzenbacher, S., Wu, J., Nowitsch, S., Steinkellner, G., et al. (2013). Fusion of binding domains to Thermobifida cellulosilytica cutinase to tune sorption characteristics and enhancing PET hydrolysis. Biomacromolecules 14, 1769-1776. doi: 10.1021/bm400140u

Roth, C., Wei, R., Oeser, T., Then, J., Follner, C., Zimmermann, W., et al. (2014). Structural and functional studies on a thermostable polyethylene terephthalate degrading hydrolase from Thermobifida fusca. Appl. Microbiol. Biotechnol. 98, 7815-7823. doi: 10.1007/s00253-014-5672-0

Rubio, M. B., Cardoza, R. E., Hermosa, R., Gutierrez, S., and Monte, E. (2008). Cloning and characterization of the Thcutl gene encoding a cutinase of Trichoderma harzianum T34. Curr. Genet. 54, 301-312. doi: 10.1007/s00294-008-0218-6

Sambrook, J., Fritsch, E. F., and Maniatis, T. (1989). Molecular Cloning: A Laboratory Manual, 2nd Edn. Cold Spring Harbor, NY: Cold Spring Harbor Laboratory Press.

Schilling, S., Hoffmann, T., Rosche, F., Manhart, S., Wasternack, C. H.-, Demuth, U. (2002). Heterologous expression and characterization of human glutaminyl cyclase: evidence for a disulfide bond with importance for catalytic activity. Biochemistry 41, 10849-10857. doi: 10.1021/bi0260381

Schmidt, J., Wei, R., Oeser, T., Belisario-Ferrari, M. R., Barth, M., Then, J., et al. (2016). Effect of Tris, MOPS, and phosphate buffers on the hydrolysis of polyethylene terephthalate films by polyester hydrolases. FEBS Open Bio 6, 919-927. doi: 10.1002/2211-5463.12097

Seman, W. M., Bakar, S. A., Bukhari, N. A., Gaspar, S. M., Othman, R., Nathan, S., et al. (2014). High level expression of Glomerella cingulata cutinase in dense cultures of Pichia pastoris grown under fed-batch conditions. J. Biotechnol. 184, 219-228. doi: 10.1016/j.jbiotec.2014.05.034

Shirke, A. N., Su, A., Jones, J. A., Butterfoss, G. L., Koffas, M. A., Kim, J. R., et al. (2017). Comparative thermal inactivation analysis of Aspergillus oryzae and Thiellavia terrestris cutinase: role of glycosylation. Biotechnol. Bioeng. 114, 63-73. doi: 10.1002/bit.26052

$\mathrm{Su}, \mathrm{L}$. , Woodard, R. W., Chen, J., and Wu, J. (2013). Extracellular location of Thermobifida fusca cutinase expressed in Escherichia coli BL21(DE3) without mediation of a signal peptide. Appl. Environ. Microbiol. 79, 4192-4198. doi: 10.1128/AEM.00239-13

Takagi, S., Tsutsumi, N., Terui, Y., and Kong, X. (2012). Method for methanol independent induction from methanol inducible promoters in Pichia in N. A/S (Ed.) US. Available online at: https://www.google.com/patents/US8236528

Then, J., Wei, R., Oeser, T., Gerdts, A., Schmidt, J., Barth, M., et al. (2016). A disulfide bridge in the calcium binding site of a polyester hydrolase increases its thermal stability and activity against polyethylene terephthalate. FEBS Open Bio 6, 425-432. doi: 10.1002/2211-5463.12053

Tokiwa, Y., Calabia, B. P., Ugwu, C. U., and Aiba, S. (2009). Biodegradability of Plastics. Int. J. Mol. Sci. 10, 3722-3742. doi: 10.3390/ijms10093722

Várnai, A., Tang, C., Bengtsson, O., Atterton, A., Mathiesen, G., and Eijsink, V. G. (2014). Expression of endoglucanases in Pichia pastoris under control of the GAP promoter. Microb. Cell Fact. 13:57. doi: 10.1186/1475-2859-13-57

Vassileva, A., Chugh, D. A., Swaminathan, S., and Khanna, N. (2001). Effect of copy number on the expression levels of hepatitis B surface antigen in the methylotrophic yeast Pichia pastoris. Protein Expr. Purif. 21, 71-80. doi: $10.1006 /$ prep. 2000.1335

Vertommen, M. A. M. E., Nierstrasz, V. A., Veer van der, M. M. M., and Warmoeskerken, C. G. (2005). Enzymatic surface modification of poly(ethylene terephthalate). J. Biotechnol. 120, 376-386. doi: 10.1016/j.jbiotec.2005.06.015

Yang, M., Yu, X. W., Zheng, H., Sha, C., Zhao, C., Qian, M., et al. (2015). Role of $\mathrm{N}$-linked glycosylation in the secretion and enzymatic properties of Rhizopus chinensis lipase expressed in Pichia pastoris. Microb. Cell Fact. 14:40. doi: 10.1186/s12934-015-0225-5

Yoon, M.-Y., Kellis, J., and Poulose, A. J. (2002). Enzymatic modification of polyester. AATCC Rev. 2, 33-36. 
Zhao, L., Geng, J., Guo, Y., Liao, X., Liu, X., Wu, R., et al. (2015). Expression of the Thermobifida fusca xylanase Xyn11A in Pichia pastoris and its characterization. BMC Biotechnol. 15:18. doi: 10.1186/s12896-015-0135-y

Zhao, W., Wang, J., Deng, R., and Wang, X. (2008). Scale-up fermentation of recombinant Candida rugosa lipase expressed in Pichia pastoris using the GAP promoter. J. Ind. Microbiol. Biotechnol. 35, 189-195. doi: 10.1007/s10295-007-0283-8

Zumstein, M. T., Kohler, H. P., McNeill, K., and Sander, M. (2016). Enzymatic hydrolysis of polyester thin films: real-time analysis of film mass changes and dissipation dynamics. Environ. Sci. Technol. 50, 197-206. doi: 10.1021/acs.est.5b04103
Conflict of Interest Statement: The authors declare that the research was conducted in the absence of any commercial or financial relationships that could be construed as a potential conflict of interest.

Copyright (C) 2017 Gamerith, Vastano, Ghorbanpour, Zitzenbacher, Ribitsch, Zumstein, Sander, Herrero Acero, Pellis and Guebitz. This is an open-access article distributed under the terms of the Creative Commons Attribution License (CC BY). The use, distribution or reproduction in other forums is permitted, provided the original author(s) or licensor are credited and that the original publication in this journal is cited, in accordance with accepted academic practice. No use, distribution or reproduction is permitted which does not comply with these terms. 